\title{
Bacterial Cell Cultures in a Lab-on-a-Disc: A Simple and Versatile Tool for Quantification of Antibiotic Treatment Efficacy
}

Serioli, Laura; Laksafoss, Trygvi Z.; Haagensen, Janus A. J.; Sternberg, Claus; Sørensen, Mads P.; Molin, Søren; Zor, Kinga; Boisen, Anja

Published in:

Analytical Chemistry

Link to article, DOI:

10.1021/acs.analchem.0c02582

Publication date:

2020

Document Version

Peer reviewed version

Link back to DTU Orbit

Citation (APA):

Serioli, L., Laksafoss, T. Z., Haagensen, J. A. J., Sternberg, C., Sørensen, M. P., Molin, S., Zor, K., \& Boisen, A. (2020). Bacterial Cell Cultures in a Lab-on-a-Disc: A Simple and Versatile Tool for Quantification of Antibiotic Treatment Efficacy. Analytical Chemistry, 92(20), 13871-13879. https://doi.org/10.1021/acs.analchem.0c02582

\section{General rights}

Copyright and moral rights for the publications made accessible in the public portal are retained by the authors and/or other copyright owners and it is a condition of accessing publications that users recognise and abide by the legal requirements associated with these rights.

- Users may download and print one copy of any publication from the public portal for the purpose of private study or research.

- You may not further distribute the material or use it for any profit-making activity or commercial gain

- You may freely distribute the URL identifying the publication in the public portal 


\title{
Bacterial Cell Cultures in a Compact Lab-on-a-Disc: a Simple and Versatile Tool for Quantification of Antibiotic Treatment Efficacy
}

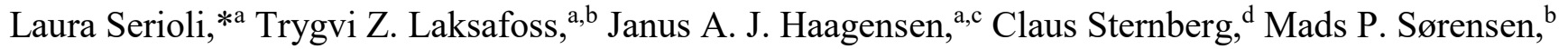 \\ Søren Molin, ${ }^{\mathrm{c}}$ Kinga Zór ${ }^{\mathrm{a} *}$ and Anja Boisen ${ }^{\mathrm{a}}$ \\ ${ }^{\text {a }}$ Center for Intelligent Drug Delivery and Sensing Using Microcontainers and Nanomechanics (IDUN), Department of \\ Health Technology, Technical University of Denmark, 2800 Kgs. Lyngby, Denmark. \\ ${ }^{\mathrm{b}}$ The Novo Nordisk Foundation Center for Biosustainability, Technical University of Denmark, 2800 Kgs. Lyngby, Den- \\ mark. \\ ${ }^{\mathrm{c}}$ Department of Biotechnology and Biomedicine, Technical University of Denmark, 2800 Kgs. Lyngby, Denmark. \\ ${ }^{\mathrm{d}}$ Department of Applied Mathematics and Computer Science, Technical University of Denmark, 2800 Kgs. Lyngby, Den- \\ mark.
}

\begin{abstract}
Pathogenic bacterial biofilms can be life threatening, greatly decrease patients' quality of life and are a substantial burden on the healthcare system. Current methods for evaluation of antibacterial treatments in clinics and in vitro systems used in drug development and screening either do not facilitate biofilm formation or are cumbersome to operate, need large reagent volumes and are costly, limiting their usability. To address these issues, this work presents the development of a robust in vitro cell culture platform compatible with confocal microscopy. The platform shaped as a compact disc, facilitates long-term bacterial culture without external pumps and tubing and can be operated for several days without additional liquid handling. As an example, Pseudomonas aeruginosa biofilm is grown from single cells and it is shown that: 1) the platform delivers reproducible and reliable results; 2) growth is dependent on flow rate and growth medium composition; and 3) efficacy of antibiotic treatment depends on the formed biofilm. This platform enables biofilm growth, quantification and treatment as in a conventional flow setup, while decreasing the application barrier of lab-on-chip systems. It provides an easy-to-use, affordable option for end users working with cell culturing in relation to e.g. diagnostics and drug screening.
\end{abstract}

Since the introduction of antibiotics for treatment of bacterial infections, microbes have developed resistance to antimicrobial agents with an alarming rate ${ }^{1,2}$ and, antibiotic resistance became one of the biggest threats to global health ${ }^{3}$. It is clear that there is a high demand for new drugs, novel therapeutic approaches ${ }^{4}$ and for reliable, robust and easy-to-use in vitro antibiotic susceptibility testing, both for the screening of new drugs and for clinical diagnostics. Additionally, the in vitro systems need to better reflect the lifestyle of bacteria in a human host, considering that bacterial biofilms, which are often representative for bacterial growth in patients, have 10-1000 fold higher tolerance towards antimicrobial agents than the same bacteria in a planktonic stage ${ }^{5-7}$. Moreover, according to the US National Institutes of Health, the majority of infections are associated with biofilms ${ }^{7}$, which are aggregations of microorganisms often found on implants ${ }^{8}$, catheters ${ }^{9}$ and on natural surfaces such as inside ears ${ }^{10}$, in lungs ${ }^{11}$ and in chronic wounds ${ }^{12}$.

Traditionally, in clinical settings, bacteria are cultivated in vitro in static systems (e.g. culture dishes), in which antibiotic susceptibility is determined using diffusion discs to estimate the minimum inhibitory concentration of the drugs ${ }^{13,14}$. These methods have defined protocols and standard procedures, but they do not mimic in vivo conditions. Although, there is no standard protocol for biofilm growth, there are a number of methods which facilitate biofilm formation ${ }^{15,16}$. The relevancy of bacterial biofilms and the finding that bacteria can form biofilm ${ }^{17}$, when grown under flow conditions with constant supply of oxygen, nutrients and removal of waste products, led to the development of various perfusion culture systems over the last decade ${ }^{18-20}$.

Although, growing bacteria under flow condition has several advantages, some of these systems rely on relatively bulky and expensive pumps for liquid movement and need tubing, to interface to a fluidic or microfluidic chip ${ }^{21,22}$. Tubing and connectors increase the dead volume in the final system, resulting in relatively high volumes (up to few 1). Additionally, microbial growth in these accessory parts can seriously disturb the central part of the biofilm, which is the de facto target of investigation.

Among the in vitro fluidic platforms, microfluidic systems have an additional benefit, since they require low (few $\mathrm{ml}$ ) operational volumes, when working with flow rates in the range from $50 \mathrm{nl} / \mathrm{min}$ to $2 \mu \mathrm{l} / \mathrm{min}^{19,23}$. These systems have successfully been used to investigate biofilm growth under varying flow rates and shear stress ${ }^{24}$, in the presence of signalling molecules ${ }^{23}$, in various microfluidic geometries ${ }^{25}$, and when exposed to antibiotic treatment ${ }^{22}$. There are also commercial products, which provide the possibility for in flow culture (e.g. 
bioreactors) ${ }^{26}$ and systems that enable biofilm growth in microfluidics ${ }^{27,28}$. However they are rather bulky, rely on pumps and have a relatively high running cost (e.g. $\sim 250 \mathrm{USD} /$ plate for the BioFlux 1000Z ${ }^{\mathrm{TM}}{ }^{28}$.

Centrifugal microfluidics or lab-on-a-disc (LoD) systems are interesting alternatives to conventional fluidic platforms, since they are compact, tubing-free, low cost, can be portable, and only use small reagent volumes (from $\mu 1$ to a few $\mathrm{ml}{ }^{29}$. In LoD, the liquid flow is controlled by centrifugal forces, enabled by a small spindle motor. By avoiding the use of pumps and tubing, it is possible to significantly decrease the introduction of bubbles in the system, and therefor bubble traps, which are commonly present in other fluidic systems ${ }^{21}$, are not needed. Additionally, there are various methods to integrate multiple operational units such as filtration, metering, mixing, and valving to enable implementation of complex chemical and biological assays ${ }^{30,31}$. LoD systems have been used for a wide range of applications including diagnostics ${ }^{32,33}$, food analysis ${ }^{34}$, sample pre-treatment ${ }^{35}$ and cell handling ${ }^{36}$. There are only few reports on application of centrifugal microfluidics for studying cells and living organisms. For instance the effect of gravitational forces was studied on LoD, using the nematode Caenorhabditis elegans, to investigate the basis of stress respond in space ${ }^{37}$. Additionally, centrifugal microfluidics was used for cell trapping and analysis ${ }^{38,39}$.

To the best of our knowledge, there are no reports on longterm culture of bacteria or studies of antibiotic treatment in biofilms on discs. Long-term culture is particularly relevant in the case of $P$. aeruginosa, since it has been shown that a mature biofilm is developed after few days of cultivation, (3-4 days), in flow ${ }^{40}$.

In this work, we developed and optimized a compact, easyto-operate centrifugal microfluidic platform for bacterial culture, which enables the formation of biofilms, similar to the ones present in infected chronic wounds, implants or in the lungs of cystic fibrosis patients (Figure 1). The Bacterial-Culture-on-disc (BCoD) device allows culture for multiple days (from 1 up to 7 days) depending on the flow rates ( 2 to 0.3 $\mu 1 / \mathrm{min}$ ) without the need of additional liquid handling. This in vitro LoD unit was successfully used for the evaluation of the effects of flow rate and growth medium composition on $P$. aeruginosa biofilm formation.

The centrifugal platform proved to be robust, reliable and provided results similar to data obtained with a conventional fluidic platform and reported in literature, while having a significantly lower degree of technical complexity then the commonly used fluidic devices. The presented compact disc format microfluidic device has the potential to decrease severe application barriers, the so-called 'chip-in-the-lab' paradigm ${ }^{41,42}$, of microfluidic technologies and become an indispensable tool for end-users (e.g. biologist, clinicians, pharmaceutical scientist). Additionally, due to the low volume of reagents required, this device would be highly relevant in the initial phase of drug screening, as well as for diagnostic purposes.

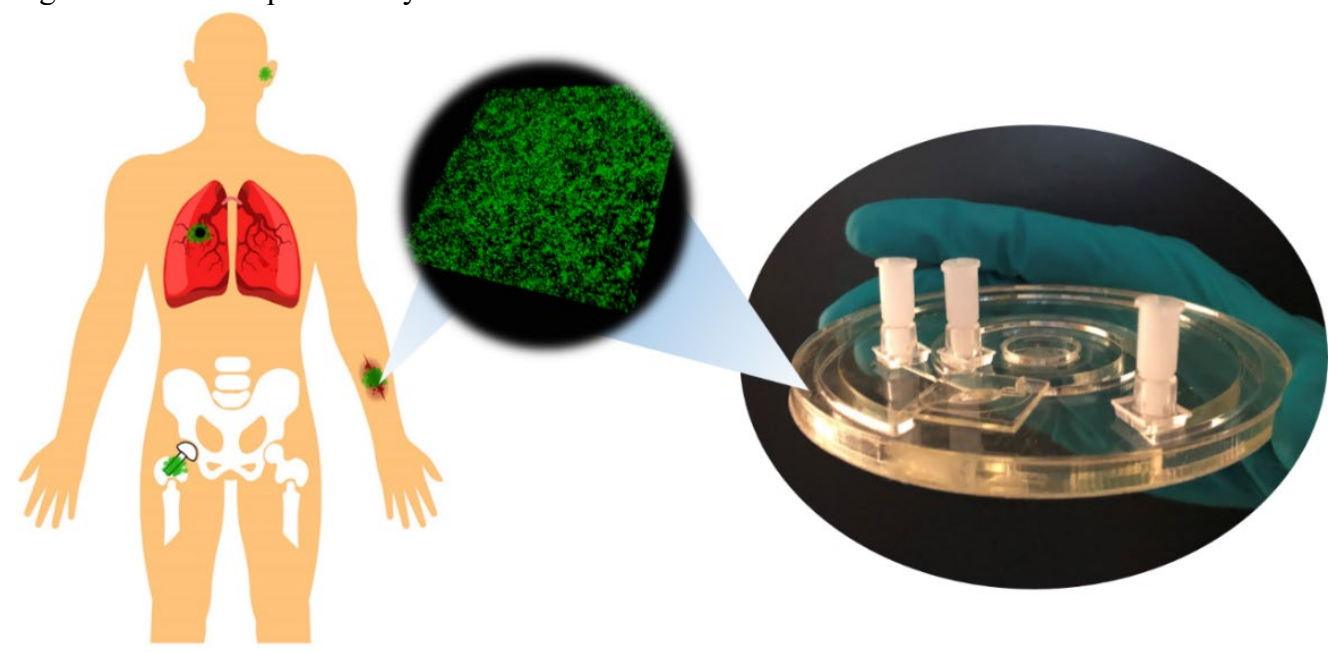

1. Schematic representation of the presence of biofilms in the lung, ear, on implant and in wound in the human body under pathological condition (left), the reproduction of $P$. aeruginosa biofilm in the centrifugal microfluidic system (middle) and the compact disc shaped lab-on-a-disc platform (right).

\section{EXPERIMENTAL SECTION}

\section{Chemicals and bacterial culture}

Overnight cultures of $P$. aeruginosa ${ }^{43}$, PAO1, were prepared in Luria Bertani (LB) medium at $37^{\circ} \mathrm{C}$, obtaining final concentrations of approximately $4 \times 10^{7}$ cells $/ \mathrm{ml}\left(\mathrm{OD}_{600}\right.$ of 0.05$)$. LB contained $10 \mathrm{~g} / 1$ bacto-tryptone, $5 \mathrm{~g} / 1$ yeast extract and $5 \mathrm{~g} / \mathrm{l}$ sodium chloride solubilized in deionized water and sterilized by autoclaving at $121{ }^{\circ} \mathrm{C}$ for $15 \mathrm{~min}$. The PAO1 strain was genetically modified by introducing a gene encoding green fluorescent protein (GFP) in the chromosome at a neutral side using Tn7 tagging ${ }^{44}$, making the bacteria fluoresce green under the microscope when exposed to a $488 \mathrm{~nm}$ light source. The minimal glucose medium (MM) for bacterial growth, (made in the lab), was composed of $1 \mathrm{mM}$ magnesium chloride, $0.1 \mathrm{mM}$ calcium chloride, 10000 times diluted trace metals $\S, 10$ times diluted $\mathrm{A} 10 \S \S$ and $0.3 \mathrm{mM}$ glucose ${ }^{45}$. To prepare $250 \mathrm{ml}$ of artificial sputum medium (ASM), (made in the lab), $1 \mathrm{~g}$ of DNA from fish sperm and $1.25 \mathrm{~g}$ of mucin from porcine stomach (type II) were dissolved in two separate bottles filled with 62.5 $\mathrm{ml}$ of sterile water overnight at $150 \mathrm{rpm}, 30^{\circ} \mathrm{C}$. As a next step the dissolved DNA from fish sperm and mucin solutions were mixed together in a new bottle. $25 \mathrm{ml}$ of essential and non (ex- 
cept 1-cysteine and l-tyrosine) essential amino acids stock solution $2.5 \mathrm{mg} / \mathrm{ml}, 6.25 \mathrm{ml}$ of l-cysteine (dissolved in $0.5 \mathrm{M}$ potassium hydroxide) and l-tyrosine (dissolved in sterile water) stock solution $10 \mathrm{mg} / \mathrm{ml}, 5 \mathrm{ml}$ of ASM salts (diethylenetriaminepentaacetic acid (DTPA) $59 \mu \mathrm{g} / \mathrm{ml}, \mathrm{NaCl} 50 \mathrm{mg} / \mathrm{ml}, \mathrm{KCl} 22 \mathrm{mg} / \mathrm{ml}$ ) and $1.25 \mathrm{ml}$ egg yolk were added and mixed with the DNA and the mucin. The final solution was sterilized using a filtration technique with a filter of $0.22 \mu \mathrm{m}$ pore size.

Propidium iodide (Sigma-Aldrich, Merck Denmark A/S, Hellerup, Denmark) was introduced in the platform to detect cells with a damaged membrane potential, indicating cell death. Ciprofloxacin hydrochloride (CIP), (Fagron, Uitgeest, The Netherlands) with a final concentration of $4 \mu \mathrm{g} / \mathrm{ml}(10 \mu \mathrm{M})$ was used for treatment of the bacterial biofilms. Sodium hydroxide (EMSURE®, Merck KGaA, Darmstadt, Germany) $500 \mathrm{mM}$ was used for disc sterilization.

\section{Sterilization of the BCoD}

The chambers and channels of the BCoD were filled with 0.5 $M$ sodium hydroxide ${ }^{46}$ using a syringe. After $20 \mathrm{~min}$, the sodium hydroxide was removed and the platform was rinsed thoroughly with sterile distilled water and with autoclaved medium, paying particular attention to remove all excess sodium hydroxide from the cell chamber. Additionally, the disc was rinsed with autoclaved medium three times using a spin stand. The sterilization process and mounting of autoclaved filters and luers on the BCoD took place in a sterile bench. Subsequently, the inoculated disc was placed on the spin stand (rotation was achieved with a spindle motor, RE 35, Maxon motor AG, Sachseln, Switzerland) in a $37^{\circ} \mathrm{C}$ incubation room. Also during the sterilization process and later for cell culture, in order to increase throughput, discs were stacked on the spin stand as shown in Figure S1a.

\section{Inoculation of bacteria}

Inoculation of bacteria in the sterilized disc was achieved by addition of $40 \mu$ l overnight culture of $P$. aeruginosa diluted to $\mathrm{OD}=0.05$ though the inoculation opening situated in close proximity to the cell culture chamber (Figure 2 iii). During inoculation, the inlet reservoir opening was closed to avoid bacteria occlusion in the serpentine channel and potentially entering the medium reservoir. To allow the bacteria to adhere in the culture chamber, the flow was stopped for $1 \mathrm{~h}$, after which a given flow (rotation) was set.

\section{Antibiotic treatment}

The bacteria were cultured for $72 \mathrm{~h}$ before antibiotic treatment. Propidium iodide was used to identify cells with compromised membrane, dead cells, in the biofilm ${ }^{47}$. Two $\mu 1$ of propidium iodide $(20 \mathrm{mM})$ were introduced in the inlet reservoir together with culture medium. Ciprofloxacin with a final concentration of $4 \mu \mathrm{g} / \mathrm{ml}(10 \mu \mathrm{M})$ was introduced after $72 \mathrm{~h}$ in the inlet reservoir. The antibiotic was added with the help of a pipette through the loading opening, in order to avoid creating a pressure on the biofilm.

\section{Data collection and analysis}

Microscopic monitoring of bacterial biofilms and effect of treatment were completed using an upright Leica (Leica SP5 CLSM, Leica Microsystems, Mannheim, Germany) equipped with an argon/krypton laser and detectors and filter sets for simultaneous monitoring of GFP (excitation: $488 \mathrm{~nm}$, emission:
493-558 nm) for live cell imaging and propidium iodide (excitation: $543 \mathrm{~nm}$, emission: $558-700 \mathrm{~nm}$ ) for dead cell staining. Images were obtained using a 50x water objective (numerical aperture 0.75). Two biological replicates were used with eighteen technical replicates in each experiment, by collecting images from different sections of the culture chamber. The confocal images were treated using IMARIS software (Bitplane AG). The collected images served as input to calculate the bacterial biomass using Comstat (Comstat, Technical University of Denmark). ${ }^{48}$ Origin 2018b (OriginLab Corp, Northampton, USA) was used to analyze and display the data.

\section{RESULTS AND DISCUSSION}

\section{Fabrication, operation and characterization of the BCoD}

The LoD device (Figure 1, 2a) was designed using Solidworks 2017 (Dassault Systémes, Vélizy-Villacoublay, France). It consists of eight layers; 4 poly(methyl methacrylate) (PMMA), 3 pressure sensitive double adhesive tape (PSA) and 1 glass. The disc has a $100 \mathrm{~mm}$ outer and a $15.35 \mathrm{~mm}$ inner diameter. The LoD was assembled from two layers of $0.60 \mathrm{~mm}$ thick PMMA (Axxicon Moulds, Eindhoven, The Netherlands), one layer of $5 \mathrm{~mm}$ thick PMMA (Nordisk plast, Randers, Denmark) and two layers $0.15 \mathrm{~mm}$ thick PSA (ARcare ${ }^{\circledR}$ 90106, Adhesive Research, Limerick, Ireland) (Figure S1b). In order to maximize the volume of the cell chamber $(55 \mu \mathrm{l})$ a layer of PMMA ( $20 \times 20 \mathrm{~mm}, 0.60 \mathrm{~mm}$ thick) was fixed using PSA on the PMMA disc layer. A $0.15 \mathrm{~mm}$ cover glass (Gerhard Menzel B.V.\&Co.KG, Braunschweig, Germany) was chosen to close the cell chamber (Figure S1b) in order to have an optimal imaging for confocal scanning laser microscopy. The PMMA layers were fabricated using laser ablation technique (Epilog Mini $1830 \mathrm{~W}$ system, Epilog, USA) except for channels and culture chamber which were manufactured with micromilling (MiniMill/3, Minitech Machinery Corp, GA, US). PMMA layers, were cleaned with sonication in ultrapure water and ethanol, then assembled with the PSA layers using a bonding press (PW $10 \mathrm{H}, \mathrm{P} / \mathrm{O} /$ Weber, Germany), with a force of $10 \mathrm{KN}$ for $1 \mathrm{~min}$. The cover glass (Figure S1b), was separately glued using a silicone glue (Super Clear Silicone, Versachem, Hartford, Connecticut, USA) and dried overnight. The shape of the channel was designed to enable good mixing of nutrients ${ }^{49}$, while the culture chamber's ( $2 \mathrm{~mm}$ deep with a total volume of $55 \mathrm{~mm}^{3}$ ) oval shape, without sharp edges, helps to avoid trapping of air bubbles (Figure 2a, b). Inlet and outlet channels ( $0.3 \mathrm{~mm}$ deep) were placed at the bottom of the culture chamber to provide sufficient space for biofilm growth and to allow continuous perfusion of nutrients. The straight outlet channel facilitates passage of waste and potentially detaching bacterial clusters (Figure 2b). A diluted bacterial culture was inoculated using a syringe needle (Hounisen Laboratorieudstyr A/S, Jystrup, Denmark), though an inoculation channel (Figure 2c iii). Filters with a 3 $\mathrm{mm}$ diameter membrane and a pore size of $0.20 \mu \mathrm{m}$ (CHROMAFIL®, Macherey-Nagel, Düren, Germany), were used to maintain a sterile environment in the disc while maintaining an oxygen flow in the platform through the pores (Figure 2a). Luer connectors were fabricated in cyclic olefin-copolymer (TOPAS grade 5013L-10, Advanced Polymers GmbH, Frankfurt-Höchst, Germany), using injection molding (Victory Tech 80/45, Engel, Schwertberg, Austria) and fixed in the venting and loading openings, facilitating the introduction of sterile filters (Figure S1a). 

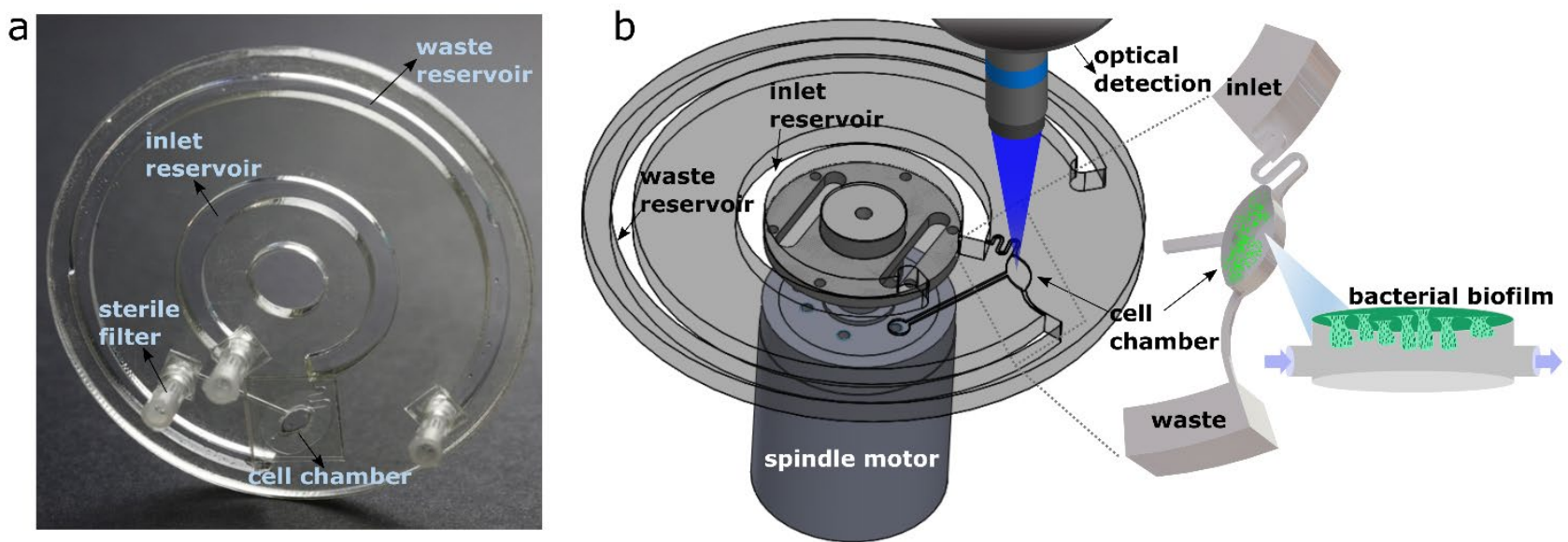

C i
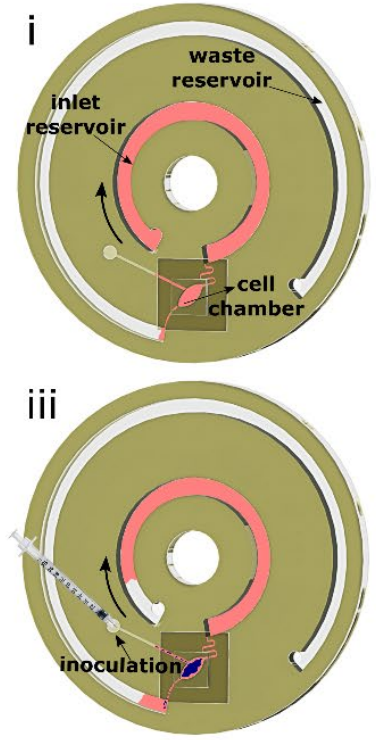

d

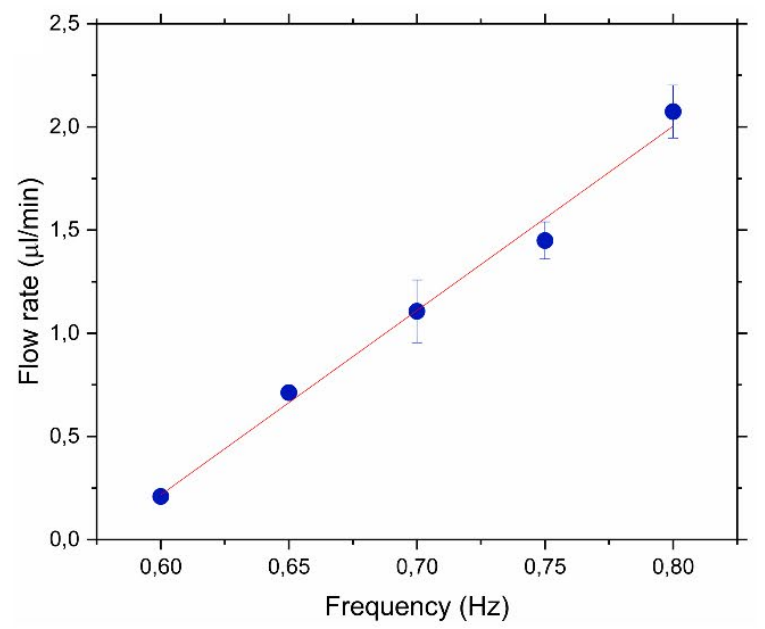

Figure 2. (a) Main operational units on the BCoD. (b) Schematic of the experimental set-up, with the BCoD combined with a spindle motor and the optical detection unit; close ups of the cell culture chamber connected to the inlet and outlet reservoir and representation of the biofilm formed in the culture chamber. (c) Fluidic operation carried out with the BCoD platform. Priming of the cell culture chamber (i) meniscus formation at $2 \mathrm{~Hz}$ and stabilization of flow at $0.63 \mathrm{~Hz}(0.3 \mu \mathrm{l} / \mathrm{min})$, or $0.70 \mathrm{~Hz}(1 \mu \mathrm{l} / \mathrm{min}) \mathrm{Hz}$ (ii). Addition of bacteria in the cell chamber (iii) and initiation of flow for long-term culturing (iv). (d) Linear dependency between rotational speed and flow rate in the BCoD.

After sterilization and placing the $\mathrm{BCoD}$ on the spin stand (Figure S1a), the inlet reservoir was filled with culture medium $(3 \mathrm{ml}$ ) and the rotational frequency was set to $2 \mathrm{~Hz}$ for a few seconds to prime the cell culture chamber and to create the front of the liquid, meniscus (Figure 2c i-ii, Video S1), followed by
$2 \mathrm{~h}$ rotation at $0.63 \mathrm{~Hz}(0.3 \mu \mathrm{l} / \mathrm{min})$ or $0.70 \mathrm{~Hz}(1 \mu \mathrm{l} / \mathrm{min})$ to stabilize the flow. After these steps the rotation of the disc was stopped, and bacteria were inoculated into the cell chamber (Figure 2c iii, Video S1). After $1 \mathrm{~h}$ in static condition, the disc was spun with a rotational frequency to achieve the required flow rate (Figure 2c iv, Video S1). The flow rate was kept constant throughout the experiment if not otherwise specified. During rotation the nutrients are perfused through the culture chamber and the waste products flow in the outlet reservoir (Figure 2c, Video S1).

Effect of shear stress, adhesion time, carbon source and flow rate on bacterial growth and biofilm formation

\section{Effect of shear stress and adhesion time}

Since it has been shown that shear stress influences bacterial cell growth ${ }^{50}$, we evaluated the shear stress caused by the liquid flow as well as the centrifugal forces during rotation. 
In COMSOL (COMSOL Multiphysics 5.3a, Stockholm, Sweden), computational fluid dynamics (CFD) simulations were used to calculate the fluid flow through the culture chamber in three spatial dimensions, in order to determine the resulting shear stress at the top of the perfusion chamber, where the formation of the bacterial biofilm is monitored. The numerical simulations are based on the mass conservation equation and the Navier-Stokes momentum equation (Supporting Information, S1).

As shown in Figure $3 a$ and $b$, the maximum wall shear stress is established in the cell chamber just after the inlet and just before the outlet. This is caused by the sudden expansion and contraction of the geometry, causing the flow velocity to locally increase and to have higher values in the central part of the cell chamber. The calculated maximum shear stress in the center is approximately an order of magnitude higher than the average shear stress in the cell culture chamber, while the highest calculated shear stress at $2 \mu 1 / \mathrm{min}(0.8 \mathrm{~Hz})$ is $0.6 \mathrm{mPa}$. A study by Park et al. ${ }^{51}$ showed that growth of $P$. aeruginosa was unaffected at shear stresses up to $17 \mathrm{mPa}$. Based on our calculations, the bacteria growing in the cell culture chamber are exposed to lower shear stresses. We therefore conclude that the flow rate, used to operate the platform, will not adversely affect the bacterial cells nor the biofilm formation.

Additionally we found that the centrifugal forces are negligible at the operational flow rates of the BCoD (Figure S3) and the flow in the centrifugal culture platform has a significant impact on the nutrient supply due to the convective transport (Supporting Information, S2).
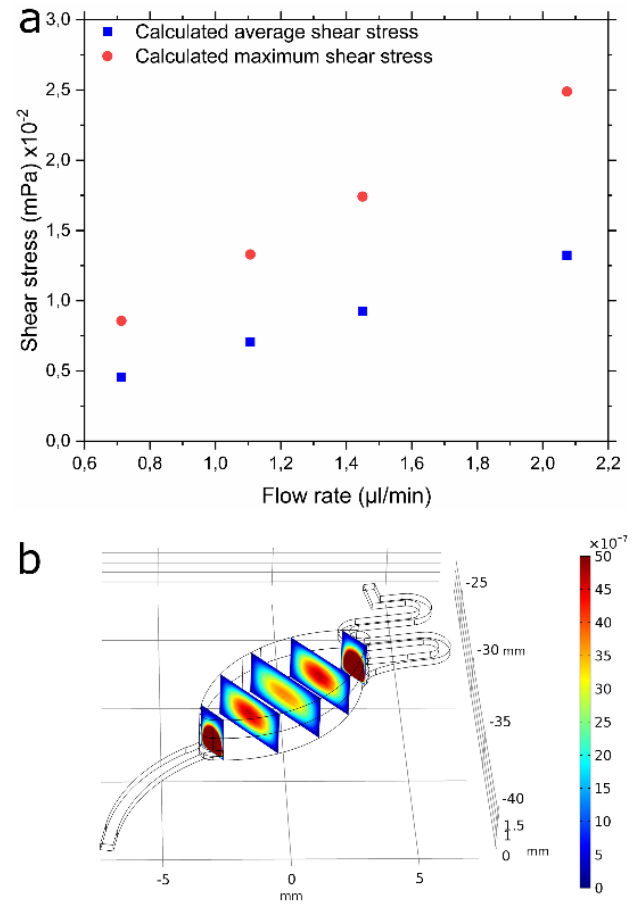

Figure 3. (a) Simulated average and maximum wall shear stress in the bacterial culture chamber. (b) Flow velocity profile in the cell chamber at $1 \mu \mathrm{l} / \mathrm{min}$ flow rate.

\section{Effect of carbon source concentration}

Considering that nutrient composition as well as the rate of nutrient and oxygen delivery affect the bacterial growth and biofilm formation ${ }^{52}$, we further investigated the effect of carbon source concentration, flow rate, and culture medium composition (MM vs. ASM) on biofilm formation.

Since it has been shown that the type and quality of carbon source (such as glucose) ${ }^{53}$ has an impact on biofilm growth, we initially cultured $P$. aeruginosa at $0.3 \mu \mathrm{l} / \mathrm{min}$ flow rate in $\mathrm{MM}$ and evaluated the effect of glucose concentration on biofilm formation. The flow rate was chosen from the linear part of the calibration curve (Figure 2d), considering that flow rates from $50 \mathrm{nl} / \mathrm{min}$ to $2 \mu \mathrm{l} / \mathrm{min}$ are commonly used in microfluidic systems for bacterial growth ${ }^{19,23}$.

In Figure 4a and $\mathrm{b}$ growth of $P$. aeruginosa for up to $24 \mathrm{~h}$ in $\mathrm{MM}$ with various glucose concentrations is presented. Biomass development after $6 \mathrm{~h}$ was independent of the concentration of glucose when assessing the effect of a 10 times $(3 \mathrm{mM})$ and a 100 times $(30 \mathrm{mM})$ increase in glucose concentration in $\mathrm{MM}$ compared to the commonly used ${ }^{21}$ one $(0.3 \mathrm{mM})$. The effect of carbon source on biomass was only visible after $24 \mathrm{~h}$. Here, the biomass increased when the glucose concentration was increased 10 and 100 times. At high concentration of glucose, especially at $30 \mathrm{mM}$, bacteria divided and created only a monolayer of cells attached to the surface (Figure 4b). An explanation for this observation could be that increasing the glucose concentration up to 100 fold reached a saturation level.

This means that bacteria reached their maximum uptake of glucose. We also observed that biofilm formation and bacterial clusters were only found in in certain region (mostly in the edges) of the chamber, while most of bacteria were still in planktonic phase (Figure 4b). Considering that the increase in glucose concentration in MM did not had clear effect on the spreading and growth of biofilm in the culture chamber, we looked at the effect of flow rate ${ }^{54}$.

\section{Effect of flow rate and different culture medium}

Figure $4 \mathrm{c}, \mathrm{d}$ shows the changes in biomass during $72 \mathrm{~h}$ using two different flow rates, low $(0.3 \mu \mathrm{l} / \mathrm{min})$ and high $(1 \mu \mathrm{l} / \mathrm{min})$ with $\mathrm{MM}$ and $1 \mu \mathrm{l} / \mathrm{min}$ in the case of ASM. In MM, at $1 \mu \mathrm{l} / \mathrm{min}$, the biomass was higher already after $6 \mathrm{~h}\left(2.9 \pm 0.6 \mu \mathrm{m}^{3} / \mathrm{mm}^{2}\right)$ compared to $0.3 \mu \mathrm{l} / \mathrm{min}\left(1.1 \pm 0.32 \mu \mathrm{m}^{3} / \mu \mathrm{m}^{2}\right)$, possibly reflecting more available nutrients and oxygen at the higher flow rate (Figure $4 \mathrm{c}$ ). It is worth to mention that at $1 \mu \mathrm{l} / \mathrm{min}$ flow rate, already at $24 \mathrm{~h}$, it was possible to observe a multi-layered biofilm in some parts of the cell chamber (Figure 4c). There is also a clear difference in the biofilm growth profile when comparing the flow rates (Figure 4c, d). Although, the effect of flow rate 
had an impact of biofilm growth, in the case of MM, the clusters and biofilm were mostly developed in close proximity of the edges of the culture chamber, which could be due to lower flow velocity profile near the wall of the cell chamber (Figure 3). Similar observations, have been already reported, when working with various culture media ${ }^{55,56}$.

Commonly, bacteria are cultured in minimal glucose medium ${ }^{45}$, but it has been shown that the ASM composition better mimics the in vivo like conditions ${ }^{57}$. Since for an in vitro biofilm assays, it is very important that the biofilm growth is reproducible and preferably uniform throughout the culture chamber we also studies the effect of ASM on biofilm growth. Previously, ASM has been used when studying biofilm formation in static systems ${ }^{58}$.

However, it is scarcely implemented in fluidic or microfluidic systems, since is rather expensive and cumbersome to prepare. Initially, when working with ASM in the BCoD, we found that with a pure as well as a 10 times diluted ASM (diluted in
MM without the addition of glucose), that after the initial adhesion to the glass surface, $P$. aeruginosa detaches and mostly grows in mucin present in the medium. Only few, rather large, clusters remain attached to the surface of the glass (Figure S5). However, in 100 times diluted ASM, the bacteria attached to the glass surface and formed biofilm throughout the culture chamber. As the optical detection and biomass quantification method used in this work, relies on attached bacteria forming biofilm on the glass surface, if not otherwise specified, we worked with 100 times diluted ASM.

Since with $\mathrm{MM}$ and $1 \mu \mathrm{l} / \mathrm{min}$, we achieved the most uniform biofilm with the highest biomass $\left(6.1 \pm 1.5 \mu \mathrm{m}^{3} / \mu \mathrm{m}^{2}\right)$, we evaluated the effect of ASM on biofilm growth at the same flow rate. In Figure 4c, when looking at the biomass growth at $1 \mu \mathrm{l} /$ min. It can be noticed, in the case of ASM, that there is more biomass starting from $24 \mathrm{~h}\left(5.1 \pm 1.2 \mu \mathrm{m}^{3} / \mu \mathrm{m}^{2}\right)$, and based on our experimental results, $P$. aeruginosa spreads more homogeneously, covering the whole culture chamber (Figure 4d).
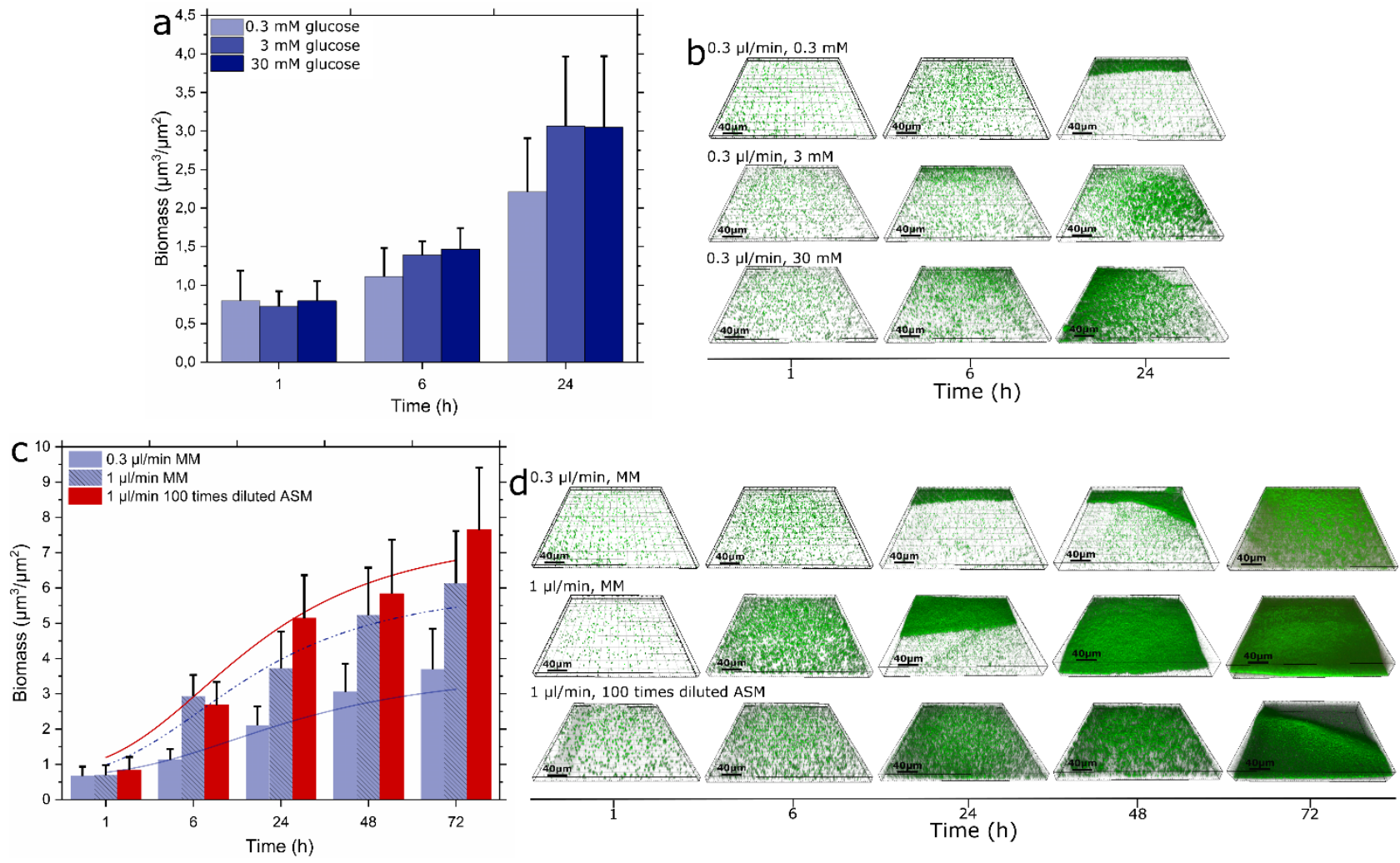

Figure 4. (a) Average biomass growth at $0.3 \mu \mathrm{l} / \mathrm{min}$ in $\mathrm{MM}$ at different glucose concentrations. Standard deviations were calculated based on $n=9$. (b) Representative images of bacterial growth observed with confocal microscope at different time points at the same location in the cell chamber. (c) Average biomass growth as function of time at $0.3 \mu \mathrm{l} / \mathrm{min}, 1 \mu \mathrm{l} / \mathrm{min}$ flow rate with $\mathrm{MM}$ and $1 \mu \mathrm{l} / \mathrm{min}$ flow rate with 100 times diluted ASM . Standard deviations were calculated based on $n=18$. (d) Representative confocal images of bacterial growth observed with confocal microscope at different time points at the same location in the cell chamber.

\section{Effect of treatment using $\mathrm{MM}$ and different flow rates}

When $P$. aeruginosa was grown in MM with a flow rate of $0.3 \mu \mathrm{l} / \mathrm{min}, 80 \pm 5.1 \%-90 \pm 9.0 \%$ of the bacteria were live at $72 \mathrm{~h}$, whereas additional $24 \mathrm{~h}$ perfusion with CIP killed $78 \pm$ $14.9 \%$ of the bacteria (Figure $5 \mathrm{a}$ ). In contrast, only $48 \pm 10.4 \%$ of the cells died when perfused with CIP at the higher flow rate $(1 \mu \mathrm{l} / \mathrm{min}$, Figure $5 \mathrm{~b})$. The higher antibiotic efficacy at the low flow rate is also evident in the confocal images presented in Figure $5 \mathrm{c}$ and $\mathrm{d}$. It is possible that the difference in cell death 
after CIP treatment is due to the difference in biomass, which was $3.7 \pm 1.2 \mu \mathrm{m}^{3} / \mu \mathrm{m}^{2}$ and $6.1 \pm 1.5 \mu \mathrm{m}^{3} / \mu \mathrm{m}^{2}$ at $72 \mathrm{~h}$ for 0.3 $\mu \mathrm{l} / \mathrm{min}$ and $1 \mu \mathrm{l} / \mathrm{min}$ flow rate.

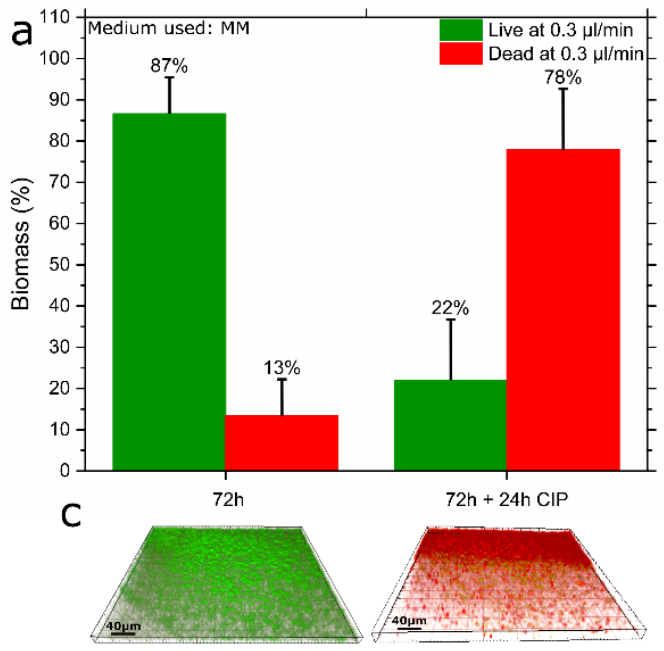

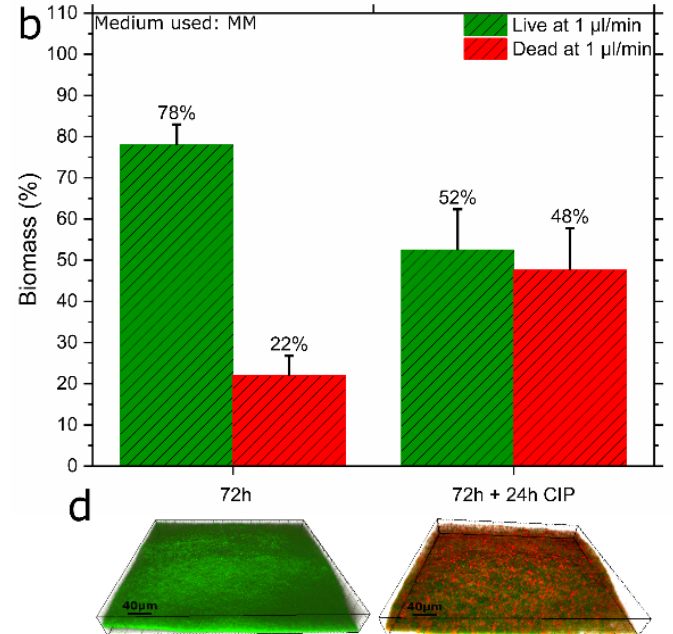

Figure 5. Biomass (a, b) and representative confocal images (c, d) of live (green) and dead (red) bacterial cells at $0.3 \mu 1 / \mathrm{min}(\mathrm{a}, \mathrm{c})$ at $1 \mu \mathrm{l} / \mathrm{min}$ (b, d) before treatment at $72 \mathrm{~h}$ and after $24 \mathrm{~h}$ antibiotic treatment at $96 \mathrm{~h}$ in MM. Standard deviations were calculated based on $\mathrm{n}=18$.

\section{Effect of treatment using ASM}
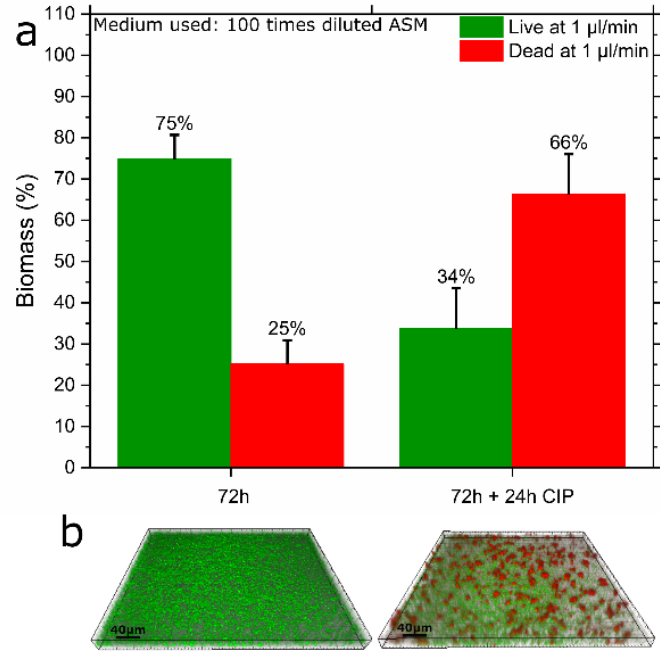

Figure 6. Biomass (a) and representative confocal images (b) of live (green) and dead (red) bacterial cells at $1 \mu \mathrm{l} / \mathrm{min}$ before treatment at $72 \mathrm{~h}$ and after $24 \mathrm{~h}$ antibiotic treatment at $96 \mathrm{~h}$ using 100 times diluted ASM as culture medium. Standard deviations were calculated based on $n=18$.

\section{Comparison with conventional flow systems}

For comparison, we also carried out experiments with an already well-established in vitro flow system ${ }^{20}$ (Figure S6) used in several studies for bacterial growth and antibiotic efficacy evaluation ${ }^{21}$. We used the same experimental conditions (culture medium (MM), cell type, CIP concentration), except the flow rate. We found that in the flow system the biomass at $72 \mathrm{~h}$ was higher $\left(15.4 \pm 4 \mu^{3} / \mu \mathrm{m}^{2}\right.$ at $200 \mu \mathrm{l} / \mathrm{min}$ vs. $6.1 \pm 1.5$ $\mu \mathrm{m}^{3} / \mu \mathrm{m}^{2}$ at $1 \mu \mathrm{l} / \mathrm{min}$ ) than in the $\mathrm{BCoD}$, probably due to the higher flow rate. However, after treatment the amount of dead biomass was comparable, $78 \pm 14.9 \%$ (Figure 5) vs $89 \pm 1.64 \%$ (Figure 7).

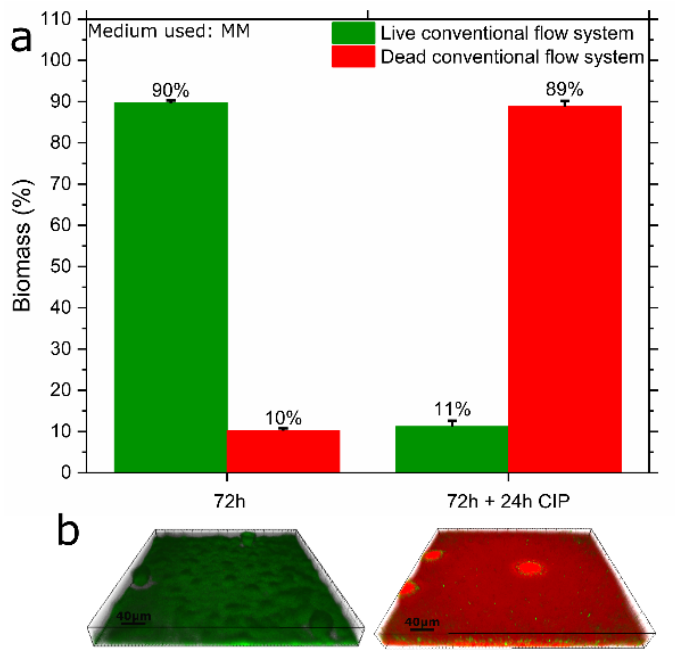

Figure 7. Biomass (a) and representative confocal images (b) of live (green) and dead (red) bacterial cells at $200 \mu \mathrm{l} / \mathrm{min}$ in the flow system before treatment at $72 \mathrm{~h}$ and after $24 \mathrm{~h}$ antibiotic treatment at 96h in MM. Standard deviations were calculated based on $n=6$. 
The low standard deviation presented in the conventional flow system is attributed to the area where the images were collected. As explained in Supporting Information, confocal images were taken only at the inlet of the chip, while in the BCoD images were taken throughout the entire cell chamber leading to higher stand deviation.

When comparing the growth of biomass in other fluidic and microfluidic systems, where $P$. aeruginosa (PAO1) was studies using the same biomass analysis method (Comstat), we found that biomass between $5 \mu \mathrm{m}^{3} / \mu \mathrm{m}^{2}$ and $12.5 \mu \mathrm{m}^{3} / \mu \mathrm{m}^{2}$ was obtained at 3 days with similar flow rates using a rich medium ${ }^{63,64}$. The reported biomass is similar to the one obtained in the BCoD platform at 3 days, namely $6.1 \pm 1.5 \mu \mathrm{m}^{3} / \mu \mathrm{m}^{2}$ at $1 \mu \mathrm{l} / \mathrm{min}$ with $\mathrm{MM}$ and $7.7 \pm 1.8 \mu \mathrm{m}^{3} / \mu \mathrm{m}^{2}$ at $1 \mu \mathrm{l} / \mathrm{min}$ flow with ASM. The growth and treatment of PAO1 biofilm with CIP was also shown in microfluidics using a BioFlux device ${ }^{22}$. Benoit et al. reported that after growing the bacteria for $8 \mathrm{~h}$ at $1.1 \mu \mathrm{l} / \mathrm{min}$ flow rate, and overnight treatment with CIP, resulted in biofilm eradication already at $0.1 \mu \mathrm{g} / \mathrm{ml}$ CIP concentration. The effect of treatment was estimated using a plate reader, measuring fluorescence signal form the green fluorescent protein tagged bacteria and propidium iodide. The biofilm eradication at the relatively low CIP concentration might indicate that after $8 \mathrm{~h}$ the biofilm was not fully mature 22,40 .

The results obtained with the $\mathrm{BCoD}$ (Figure 5, 6), clearly show that it is not possible to achieve $100 \%$ biofilm eradication of mature biofilms after $72 \mathrm{~h}$ growth. This is in accordance with previously obtained findings ${ }^{65}$, which showed that bacterial biofilm and in particular those developed by $P$. aeruginosa are tolerant to treatment with even high concentrations of antibiotics. As observed earlier $P$. aeruginos $a$ can be eradicated with $0.125 \mu \mathrm{g} / \mathrm{ml}$ of ciprofloxacin for planktonic phase, however when it forms biofilm it becomes up to 10-1000 times more tolerant to antibiotic treatment, in fact $4 \mu \mathrm{g} / \mathrm{ml}$ are needed in order to reach the minimal biofilm inhibitory concentration ${ }^{66}$.

\section{CONCLUSIONS}

We have developed a portable centrifugal microfluidic platform for bacterial culture and biofilm formation, which can be used with conventional confocal scanning laser microscopy. The presented $\mathrm{BCoD}$ is the first centrifugal platform where long-term bacterial culture, biofilm formation and antibiotic treatment have been realized.

We show that $P$. aeruginosa forms biofilms in the centrifugal microfluidic platform, which respond to conditions of varying flow rates, concentrations of carbon source and medium composition. We also show that antibiotic treatment efficacy strongly depends on growth condition in the biofilm.

Compared to other microfluidic systems, the $\mathrm{BCoD}$ is significantly easier to handle and to operate, without the need for external pumps and tubing for connections and interfacing. This in vitro platform requires considerably lower volumes of reagents, an important feature when developing and screening for new antibiotics. Additionally, the low operation volumes enables working with ASM, which better mimic the in vivo like conditions, commonly not used in fluidic systems, due to high costs because of large volumes.

Most importantly, the platform delivers results similar to tried and tested conventional platforms and is useful for reproducible semi-high-throughput culturing and testing.
Furthermore, the BCoD has the potential for multiplexing by integration of additional culture units and stacking of the discs.

In the future, we will explore the $\mathrm{BCoD}$ for fundamental studies of biofilm behavior, as well as for screening of different biofilm eradication strategies in clinical isolates.

Our results suggest that the developed LoD system has the potential to be implemented as a general in vitro platform for studying bacterial biofilms, for tests of novel antimicrobial drugs, and for diagnostic purposes in clinical settings. Moreover, future optical detection units can be integrated in this platform.

\section{ASSOCIATED CONTENT}

\section{Supporting Information}

The Supporting Information is available free of charge on the ACS Publications website.

Components of the microfluidic system and photo of two assembled and stacked units, video of the fluidic operation of the Bacterial-Culture-on-Disc $(\mathrm{BCoD})$, calibration curve of the $\mathrm{BCoD}$, formulas used for the fluidic simulation in the cell chamber, centrifugal forces and contribution of convective mass transport, biomass attachment in cell chamber, $P$. aeruginos a growth in pure artificial sputum medium (ASM) and photo of the conventional flow system in comparison with the BCoD. (PDF and AVI)

\section{AUTHOR INFORMATION}

\section{Corresponding Author}

*Laura Serioli. Center for Intelligent Drug Delivery and Sensing Using Microcontainers and Nanomechanics (IDUN), Department of Health Technology, technical University of Denmark, 2800, Kgs. Lyngby, Denmark. E-mail: lauser@dtu.dk

*Kinga Zór. Center for Intelligent Drug Delivery and Sensing Using Microcontainers and Nanomechanics (IDUN), Department of Health Technology, technical University of Denmark, 2800, Kgs. Lyngby, Denmark. E-mail: kinzo@dtu.dk

\section{Author Contributions}

All authors have given approval to the final version of the manuscript.

\section{ACKNOWLEDGMENT}

This work was supported by the Danish National Research Foundation (DNRF122) and Villum Fonden (Grant No. 9301) for Intelligent Drug delivery and sensing Using microcontainers and Nanomechanics (IDUN).

Notes

$\S 10.000 \mathrm{x}$ Trace metals: CaSO4*2H2O (200 mg/L $)$, FeSO4*7H2O (200 mg/L), MnSO$^{2} * \mathrm{H} 2 \mathrm{O} \quad(20 \mathrm{mg} / \mathrm{L})$, $\mathrm{CuSO} 4 * 5 \mathrm{H} 2 \mathrm{O} \quad(20 \mathrm{mg} / \mathrm{L}), \quad \mathrm{ZnSO} 4 * 7 \mathrm{H} 2 \mathrm{O} \quad(20 \mathrm{mg} / \mathrm{L})$, $\mathrm{CoSO} 4 * 7 \mathrm{H} 2 \mathrm{O}(10 \mathrm{mg} / \mathrm{L}), \mathrm{NaMoO} 4 * \mathrm{H} 2 \mathrm{O}(5 \mathrm{mg} / \mathrm{L}), \mathrm{H} 3 \mathrm{BO} 3(5$ $\mathrm{mg} / \mathrm{L})$. Suspended in deionized water and autoclaved.

$\S \S$ A10: (NH4)2SO4 (20 g/L), Na2HPO4 (60 g/L), KH2PO4 (30 $\mathrm{g} / \mathrm{L}), \mathrm{NaCl}(30 \mathrm{~g} / \mathrm{L})$. Suspended in deionized water and adjusted to $\mathrm{pH} 6.4 \pm 0.1$.

\section{REFERENCES}

(1) Davies, J.; Davies, D. Origins and Evolution of Antibiotic Resistance. Microbiol. Mol. Biol. Rev. 2010, 74 (3), 1092-2172.

(2) Lee Ventola, C. The Antibiotic Resistance Crisis Part 1: Causes and Threats. Pharm. Ther. 2015, 40 (4), 277-283.

(3) World Health Organization. Antibiotic resistance 
https:/www.who.int/news-room/fact-sheets/detail/antibioticresistance (accessed Nov 27, 2019).

Parish, T. Expert Opinion on Drug Discovery Steps to Address Anti-Microbial Drug Resistance in Today's Drug Discovery. Expert Opin. Drug Discov. 2019, 14, 91-94.

Costerton, H. A. and J. W. Enhanced Activity of Combination of Tobramycin and Piperacillin for Eradication of Sessile Biofilm Cells of Pseudomonas Aeruginosa. Antimicrob. Agents Chemother. 1990, 34 (9), 1666-1671.

(6) Kumon, H.; Tomochika, K. I.; Matunaga, T.; Ohmori, H.; Ogawa, M. A Sandwich Cup Method for the Penetration Assay of Antimicrobial Agents through Pseudomonas Exopolysaccharides. Microbiol. Immunol. 1994, 38 (8), 615-619.

(12) Kirketerp-Møller, K.; Jensen, P. Ø.; Fazli, M.; Madsen, K. G.; Pedersen, J.; Moser, C.; Tolker-Nielsen, T.; Høiby, N.; Givskov, M.; Bjarnsholt, T. Distribution, Organization, and Ecology of Bacteria in Chronic Wounds. J. Clin. Microbiol. 2008, 46 (8), 2717-2722.

(13) La Tourette Prosser, B.; Taylor, D.; Dix, A. B.; Cleeland, R. Method of Evaluating Effects of Antibiotics on Bacterial Biofilm. Antimicrob. Agents Chemother. 1987, 31, 1502-1506.

(14) Stepanovic, S.; Vukovic, D.; Hola, V.; Di Bonaventura, Giovanni Djukic, S.; Cirkovic, Ivana and Ruzicka, F. Quantification of Biofilm in Microtiter Plates: Overview of Testing Conditions and Practical Recommendations for Assessment of Biofilmproduction by Staphylococci. Acta Pathol. Microbiol. Immunol. Scand. 2007, 115, 891-899.

(15) Azeredo, J.; Azevedo, N. F.; Briandet, R.; Cerca, N.; Coenye, T.; Rita Costa, A.; Desvaux, M.; Di Bonaventura, G.; Hébraud, M.; Jaglic, Z.; Kačániová, M.; Knøchel, S.; Lourenço, A.; Mergulhão, F.; Louise Meyer, R.; Nychas, G.; Simões, M.; Tresse, O.; Sternberg, C. Critical Review on Biofilm Methods. Crit. Rev. Microbiol. 2017, 43 (3), 313-351.

(16) Magana, M.; Sereti, C.; Ioannidis, A.; Mitchell, C. A.; Ball, A. R.; Magiorkinis, E.; Chatzipanagiotou, S.; Hamblin, M. R.; Hadjifrangiskou, M.; Tegos, G. P. Options and Limitations in Clinical Investigation of Bacterial Biofilms. Clin. Microbiol. Rev. 2018, 31 (3), 1-49.

(17) Keogh, M. B.; Partap, S.; Daly, J. S.; O’Brien, F. J. Three Hours of Perfusion Culture Prior to 28 Days of Static Culture, Enhances Osteogenesis by Human Cells in a Collagen GAG Scaffold. Biotechnol. Bioeng. 2011, 108 (5), 1203-1210.

(18) McBain, A. J. In Vitro Biofilm Models: An Overview. Adv. Appl. Microbiol. 2009, 69, 99-132.

(19) Kim, K. P.; Kim, Y.-G.; Choi, C.-H.; Kim, H.-E.; Lee, S.-H.; Chang, W.-S.; Lee, C.-S. In Situ Monitoring of Antibiotic Susceptibility of Bacterial Biofilms in a Microfluidic Device. Lab Chip 2010, 10 (23), 3296.

(20) Tolker-Nielsen, T.; Sternberg, C. Growing and Analyzing Biofilms in Flow Chambers. Curr. Protoc. Microbiol. 2011, 21 (1), 1B.2.1-1B.2.17.

(21) Haagensen, J. A. J.; Verotta, D.; Huang, L.; Spormann, A.; Yang, K. New in Vitro Model to Study the Effect of Human Simulated Antibiotic Concentrations on Bacterial Biofilms. Antimicrob. Agents Chemother. 2015, 59 (7), 4074-4081.
Benoit, M. R.; Conant, C. G.; Ionescu-Zanetti, C.; Schwartz, M.; Matin, A. New Device for High-Throughput Viability Screening of Flow Biofilms. Appl. Environ. Microbiol. 2010, 76 (13), 41364142 .

(23) Kim, J.; Hegde, M.; Kim, S. H.; Wood, T. K.; Jayaraman, A. A Microfluidic Device for High Throughput Bacterial Biofilm Studies. Lab Chip 2012, 12 (6), 1157.

(24) Lee, J.-H.; Kaplan, J. B.; Lee, W. Y. Microfluidic Devices for Studying Growth and Detachment of Staphylococcus Epidermidis Biofilms. Biomed Microdevices 2008, 10, 489-498.

(25) Cho, H.; Jönsson, H.; Campbell, K.; Melke, P.; Williams, J. W.; Jedynak, B.; Stevens, A. M.; Groisman, A.; Levchenko, A. SelfOrganization in High-Density Bacterial Colonies: Efficient Crowd Control. PLoS Biol. 2007, 5 (11), 302.

(26) Biosurface Technologies. BioSurface Technologies - Biofilm Reactors and Flow Cells https://biofilms.biz/ (accessed Feb 12, 2020).

(27) ibidi. ibidi Bio-Films https://ibidi.com/content/186-bio-films (accessed Feb 12, 2020).

(28) Fluxicon. Fluxion Biosciences - Cellular Analysis https://bioflux.fluxionbio.com/home-1 (accessed Feb 12, 2020).

(29) Duffy, D. C.; Gillis, H. L.; Lin, J.; Sheppard, N. F.; Kellogg, G. J.; Bioscience, G.; Avenue, B. Microfabricated Centrifugal Microfluidic Systems : Characterization and Multiple Enzymatic Assays. Anal. Chem. 1999, 71 (20), 4669-4678.

(30) Strohmeier, O.; Keller, M.; Schwemmer, F.; Zehnle, S.; Mark, D.; von Stetten, F.; Zengerle, R.; Paust, N. Centrifugal Microfluidic Platforms: Advanced Unit Operations and Applications. Chem. Soc. Rev. 2015, 44 (17), 6187-6229.

(31) Ducrée, J.; Haeberle, S.; Lutz, S.; Pausch, S.; Von Stetten, F.; Zengerle, R. The Centrifugal Microfluidic Bio-Disk Platform. J. Micromechanics Microengineering 2007, 17, 103-115.

(32) Lee, B. S.; Lee, Y. U.; Kim, H.-S.; Kim, T.-H.; Park, J.; Lee, J.G.; Kim, J.; Kim, H.; Lee, W. G.; Cho, Y.-K. Fully Integrated Lab-on-a-Disc for Simultaneous Analysis of Biochemistry and Immunoassay from Whole Blood. Lab Chip 2011, 11 (1), 70.

(33) Burger, R.; Amato, L.; Boisen, A. Detection Methods for Centrifugal Microfluidic Platforms. Biosens. Bioelectron. 2016, 76, 54-67.

(34) Kim, T.; Park, J.; Kim, C.; Cho, Y. Fully Integrated Lab-on-aDisc for Nucleic Acid Analysis of Food- Borne Pathogens. Anal. Chem. 2014, 86, 3841-3848.

(35) Morelli, L.; Serioli, L.; Centorbi, F. A.; Jendresen, C. B.; Matteucci, M.; Ilchenko, O.; Demarchi, D.; Nielsen, A. T.; Zór, K.; Boisen, A. Injection Molded Lab-on-a-Disc Platform for Screening of Genetically Modified E. Coli Using Liquid-liquid Extraction and Surface Enhanced Raman Scattering. Lab Chip 2018, 18, 869-877.

(36) Seo, J.; Yoo, J.-C. Lab-on-a-Disc Platform for Automated Chemical Cell Lysis. Sensor 2018, 18, 1-12.

(37) Kim, N.; Dempsey, C. M.; Zoval, J. V; Sze, J.-Y.; Madou, M. J. Automated Microfluidic Compact Disc (CD) Cultivation System of Caenorhabditis Elegans. Sensors Actuators B 2007, 122, 511518.

(38) King, D.; Loftus, J.; Ferreira, R.; Keating, K.; Glennon, T.; Fallon-Doran, J.; Currell, R. V.-B.; Capella Roca, B.; Doolan, P.; Ducreé, J. Single Cell Analysis Microfluidic Device for Cell Line Optimisation in Upstream Cell Culture Processing Biopharamceutical Applications. 2019 20th Int. Conf. Solid-State Sensors, Actuators Microsystems $1 \&$ Eurosensors XXXIII 2019, 8 (June), 1025-1027.

(39) Sanger, K.; Zór, K.; Bille Jendresen, C.; Heiskanen, A.; Amato, L.; Toftgaard Nielsen, A.; Boisen, A. Lab-on-a-Disc Platform for Screening of Genetically Modified E. Coli Cells via Cell-Free Electrochemical Detection of p-Coumaric Acid. Sensors Actuators B Chem. 2017, 253, 999-1005.

(40) Rasamiravaka, T.; Labtani, Q.; Duez, P.; Jaziri, M. El. The Formation of Biofilms by Pseudomonas Aeruginosa: A Review of the Natural and Synthetic Compounds Interfering with Control Mechanisms. Biomed Res. Int. 2015, 2015, 759348.

(41) Mohammed, M. I.; Haswell, S.; Gibson, I. Lab-on-a-Chip or Chip-in-a-Lab: Challenges of Commercialization Lost in Translation. Procedia Technol. 2015, 20, 54-59. 
Dekker, S.; Kubra Isgor, P.; Feijten, T.; Segerink, L. I.; Odijk, M From Chip-in-a-Lab to Lab-on-a-Chip: A Portable Coulter Counter Using a Modular Platform. Microsystems Nanoeng. 2018, 4 (1), 34 .

(43) Holloway, B. W.; Morgan, A. F. Genome Organization in Pseudomonas. Annu. Rev. Microbiol. 1986, 40, 79-105.

(44) Lambertsen, L.; Sternberg, C.; Molin, S. Mini-Tn7 Transposons for Site-Specific Tagging of Bacteria with Fluorescent Proteins. Environ. Microbiol. 2004, 6 (7), 726-732.

(45) Pamp, S. J.; Tolker-Nielsen, T. Multiple Roles of Biosurfactants in Structural Biofilm Development by Pseudomonas Aeruginosa. J. Bacteriol. 2007, 189 (6), 2531-2539.

(46) Caviglia, C.; Zór, K. Z.; Montini, L.; Tilli, V.; Canepa, S.; Melander, F.; Muhammad, H. B.; Carminati, M.; Ferrari, G.; Raiteri, R.; Heiskanen, A.; Andresen, T. L.; Emneús, J. Impedimetric Toxicity Assay in Microfluidics Using Free and Liposome-Encapsulated Anticancer Drugs. Anal. Chem. 2015, 87, 2204-2212.

(47) Boulos, L.; Prévost, M.; Barbeau, B.; Coallier, J.; Desjardins, R. LIVE/DEAD(®) BacLight(TM): Application of a New Rapid Staining Method for Direct Enumeration of Viable and Total Bacteria in Drinking Water. J. Microbiol. Methods 1999, 37, 7786.

(48) Heydorn, A.; Nielsen, A. T.; Hentzer, M.; Sternberg, C.; Givskov, M.; Ersbøll, B. K.; Molin, S. Quantification of Biofilm Structures by the Novel Computer Program COMSTAT. Microbiol. Soc. 2000, 146, 2395-2407.

(49) Madou, M.; Zoval, J.; Jia, G.; Kido, H.; Kim, J.; Kim, N. Lab on a CD. Annu. Rev. Biomed. Eng. 2006, 8 (1), 601-628.

(50) Kim, M. K.; Ingremeau, F.; Zhao, A.; Bassler, B. L.; Stone, H. A. Local and Global Consequences of Flow on Bacterial Quorum Sensing HHS Public Access Author Manuscript. Nat. Microbiol. 2016, 1,15005 .

(51) Park, A.; Jeong, H.-H.; Lee, J.; Kim, K. P.; Lee, C.-S. Effect of Shear Stress on the Formation of Bacterial Biofilm in a Microfluidic Channel. BioChip J. 2011, 5 (3), 236-241.

(52) Bester, E.; Kroukamp, O.; Hausner, M.; Edwards, E. A.; Wolfaardt, G. M. Biofilm Form and Function: Carbon Availability Affects Biofilm Architecture, Metabolic Activity and Planktonic Cell Yield. J. Appl. Microbiol. 2010, 110, 387398.

(53) Mayo, A. W.; Noike, T. Effect of Glucose Loading on the Growth Behavior of Chlorella Vulgaris and Heterotrophic Bacteria in Mixed Culture. Water Res. 1994, 28, 1001-1008.

(54) Pereira, M. O.; Kuehn, M.; Wuertz, S.; Neu, T.; Melo, L. F. Effect of Flow Regime on the Architecture of APseudomonas Fluorescens Biofilm. Biotechnol. Bioeng. 2002, 78 (2), 164-171.

(55) Yawata, Y.; Nguyen, J.; Stocker, R.; Rusconi, R. Microfluidic Studies of Biofilm Formation in Dynamic Environments. J. Bacteriol. 2016, 198, 2589-2595.

(56) Rusconi, R.; Guasto, J. S.; Stocker, R. Bacterial Transport
Suppressed by Fluid Shear. Nat. Phys. 2014, 10, 212-217.

Stevens, D. A.; Moss, R. B.; Hernandez, C.; Clemons, K. V.; Martinez, M. Effect of Media Modified to Mimic Cystic Fibrosis Sputum on the Susceptibility of Aspergillus Fumigatus, and the Frequency of Resistance at One Center. Antimicrob. Agents Chemother. 2016, 60 (4), 2180-2184.

(58) Kirchner, S.; Fothergill, J. L.; Wright, E. A.; James, C. E.; Mowat E.; Winstanley, C. Use of Artificial Sputum Medium to Test Antibiotic Efficacy against Pseudomonas Aeruginosa in Conditions More Relevant to the Cystic Fibrosis Lung. J. Vis. Exp. 2012, No. 64, 1-8.

(59) Mohan, R.; Mukherjee, A.; Sevgen, S. E.; Sanpitakseree, C.; Lee, J.; Schroeder, C. M.; Kenis, P. J. A. A Multiplexed Microfluidic Platform for Rapid Antibiotic Susceptibility Testing. Biosens. Bioelectron. 2013, 49, 118-125.

(60) Rubio, T. T.; Shapiro, C. Ciprofloxacin in the Treatment of Pseudomonas Infection in Cystic Fibrosis Patients. J. Antimicrob. Chemother. 1986, 18 (Supplement D), 147-152.

(61) Wassermann, T.; Jørgensen, K. M.; Ivanyshyn, K.; Bjarnsholt, T.; Hossein Khademi, S. M.; Jelsbak, L.; Høiby, N.; Ciofu, O. The Phenotypic Evolution of Pseudomonas Aeruginosa Populations Changes in the Presence of Subinhibitory Concentrations of Ciprofloxacin. Microbiol. (United Kingdom) 2016, 162 (5), 865875.

(62) Haagensen, J. A. J.; Klausen, M.; Ernst, R. K.; Miller, S. I.; Folkesson, A.; Tolker-Nielsen, T.; Molin, S. Differentiation and Distribution of Colistin-and Sodium Dodecyl Sulfate-Tolerant Cells in Pseudomonas Aeruginosa Biofilms. J. Bacteriol. 2007, 189 (1), 28-37.

(63) Norris, P.; Noble, M.; Francolini, I.; Vinogradov, A. M.; Stewart, P. S.; Ratner, B. D.; Costerton, J. W.; Stoodley, P. Ultrasonically Controlled Release of Ciprofloxacin from Self-Assembled Coatings on Poly(2-Hydroxyethyl Methacrylate) Hydrogels for Pseudomonas Aeruginosa Biofilm Prevention. Antimicrob. Agents Chemother. 2005, 49 (10), 4272-4279.

(64) Varadarajan, A. R.; Allan, R. N.; Valentin, J. D. P.; Ocampo, O E. C.; Somerville, V.; Pietsch, F.; Buhmann, M. T.; West, J.; Skipp, P. J.; Van Der Mei, H. C.; Ren, Q.; Schreiber, F.; Webb, J. S.; Ahrens, C. H. An Integrated Model System to Gain Mechanistic Insights into Biofilm Formation and Antimicrobial Resistance Development in Pseudomonas Aeruginosa MPAO1. bioRxiv 2020.

(65) Høiby, N.; Bjarnsholt, T.; Givskov, M.; Molin, S.; Ciofu, O. Antibiotic Resistance of Bacterial Biofilms. Int. J. Antimicrob. Agents 2010, 35 (4), 322-332.

(66) Wang, H.; Wu, H.; Song, Z.; Høiby, N. Ciprofloxacin Shows Concentration-Dependent Killing of Pseudomonas Aeruginosa Biofilm in Vitro. J. Cyst. Fibros. 2010, 9, S41.

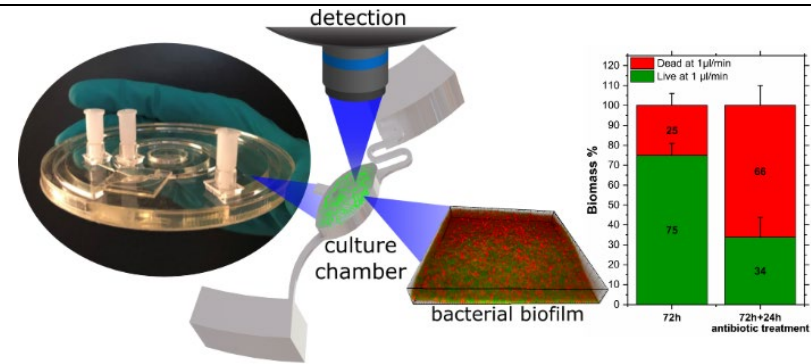

For Table of Contents Only 